\title{
Polymer-Supported Terpyridine-Palladium Complex for the Aminocarbonylation in Water of Aryl Iodines Using Methoxylamine Hydrochloride as an Ammonia Equivalent
}

\author{
Toshimasa Suzuka ${ }^{*}$, Hiromu Sueyoshi, and Kazuhito Ogihara \\ Department of Chemistry, Biology and Marine Science, University of the Ryukyus, Nishihara, \\ Okinawa 903-0213, Japan, \\ * Corresponding author: Fax: 81-098-895-8531, e-mail: suzuka@sci.u-ryukyu.ac.jp
}

\begin{abstract}
A novel homogeneous transition-metal catalyst, a polymer-supported terpyridine-palladium(II) complex, was found to promote the aminocarbonylation of aryl iodines using methoxylamine under phosphine-free conditions in water with good yield. The catalyst was recovered and reused several times without loss of catalytic activity. To our knowledge, this is the first example of polymer-supported, palladium-catalyzed synthesis of primary amides by aminocarbonylation of aryl iodides and methoxylamine under phosphine-free conditions in water.
\end{abstract}

Key words: aminocarbonylation, palladium, terpyridine, water, phosphine-free

\section{INTRODUCTION}

Primary aromatic amides are important compounds present in many natural products, are biologically active, and are useful in engineering materials such as conductive polymers [1]. Primary amides are useful as synthetic equivalents of primary amines via reduction and nitriles via dehydration [2-3]. In general, primary amides are prepared via the reaction of acid chlorides or acid anhydrides with amines and the hydration of nitriles [4].

Recently, transition-metal-catalyzed carbonylation has been developed as an alternative for the preparation of aromatic primary amides. Since Heck reported the homogeneous palladium-catalyzed carbonylation of aryl halides with carbon monoxide and nucleophiles [5], a variety of carbonylation methodologies have been reported [6].

Homogeneous catalysts generally comprise transition metals and phosphine ligands; these catalysts have been employed for carbonylation along with different ammonia equivalents as nucleophilic counterparts. Compared with phosphine ligands, other types of ligands $(\mathrm{N}, \mathrm{O}, \mathrm{S}$, etc.) for carbonylation chemistry have not received much attention. In addition, the preparation of aromatic primary amides via transition-metal-catalyzed carbonylation has also been relatively overlooked, compared with secondary and tertiary amide preparations.

Recently, Gadge and Bhanage reported the palladium-catalyzed synthesis of primary aromatic amides using carbon monoxide and methoxylamine hydrochloride as an ammonia equivalent under phosphine-free conditions [7]. However, three principal drawbacks of the reported protocol exist, despite having considered the environmental impact and cost for the reported reaction: (1) The expensive palladium catalyst needs to be disposed after being used a few times. (2) The products might get contaminated. (3) An expensive toxic organic solvent such as acetonitrile is used.
On the other hand, we recently developed an amphiphilic polystyrene-poly(ethylene glycol) (PS-PEG) resin-supported terpyridine-palladium complex as a phosphine-free catalyst and found it to be effective for metal-catalyzed reactions in water under heterogeneous and aerobic conditions with high recyclability [8]. As an extension of that study, we investigated the catalytic utility of the PS-PEG-terpyridine-palladium(II) complex for the carbonylation of aryl halides using an ammonium equivalent to produce primary amides in water [9].

We herein report the results of this investigation and demonstrate that the complex effectively catalyzes the aminocarbonylation of various aryl halides with carbon monoxide in water under phosphine-free conditions (Scheme 1). This catalyst system presents three benefits: (1) It produces neither organic-solvent waste nor metal-contaminated waste. (2) It is unharmed by oxygen and moisture. (3) It enables the aminocarbonylation reaction to meet green chemical requirements.

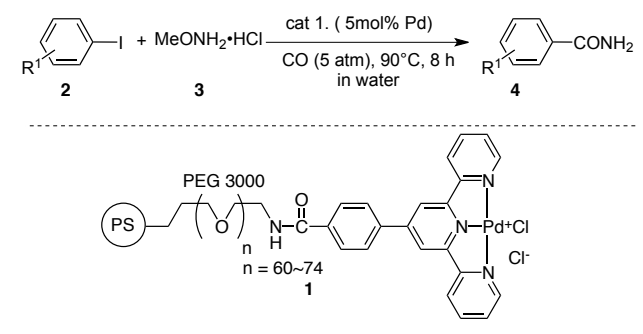

Scheme 1. Aminocarbonylation Reaction in Water Using the PS-PEG-Terpyridine-Pd Complex

\section{EXPERIMENTAL SECTION}

\subsection{General Methods}

All manipulations were conducted under aerobic conditions. Water was deionized with a Millipore Milli-Q Gradient A10 system. NMR spectra were 
recorded on a Bruker AVANCE spectrometer $(400 \mathrm{MHz}$ for ${ }^{1} \mathrm{H}$ and $100 \mathrm{MHz}$ for $\left.{ }^{13} \mathrm{C}\right) .{ }^{1} \mathrm{H}$ and ${ }^{13} \mathrm{C}$ spectra were recorded in dimethyl sulfoxide- $d_{6}$ (DMSO- $d_{6}$ ) at $25{ }^{\circ} \mathrm{C}$. Chemical shifts of ${ }^{13} \mathrm{C}$ are given relative to $\mathrm{CDCl} 3$ and DMSO $-d_{6}$ as an internal standard ( $\left.\delta 39.7 \mathrm{ppm}\right)$. Mass spectra were measured on a JEOL JMS-T100GCv MS detector (GC-MS) and a JEOL JMS-T100LP MS detector (LC-MS); the base peak is denoted as "bp." GC and IR analyses were performed on a Shimadzu GC-2014 and a Jasco FTIR-410 detector, respectively. ICP-AES spectra were measured on a Shimadzu ICPE-9000. The high-pressure reaction was performed on an EYELA HIP-7506 autoclave.

\subsection{Materials}

PS-PEG-supported terpyridine-palladium complex (PS-PEG-terpyridine-Pd; 1) was prepared from a PS-PEG amino-resin (Tenta Gel S NH2, average diameter is $90 \mathrm{~mm}, 1 \%$ divinylbenzene cross-linked, loading value of amino residue $0.31 \mathrm{mmol} / \mathrm{g}$; purchased from Rapp Polymer), polymeric terpyridine ligand, and $\left(\mathrm{C}_{6} \mathrm{H}_{5} \mathrm{CN}\right)_{2} \mathrm{PdCl}_{2}$ in accordance with previously reported procedures $[8,10]$. The loading level of $\mathrm{Pd}$ in polymeric catalyst 1 was $0.26 \mathrm{mmol} / \mathrm{g}$.

\subsection{Synthesis of polymer-supported ligand}

A solution of aqueous $\mathrm{NH}_{4} \mathrm{OH}(28 \%, 0.2 \mathrm{~mL})$ and $\mathrm{NaOH}(80 \mathrm{mg}, 2.0 \mathrm{mmol})$ in minimal water was added to a solution of 4-methoxycarbonylbenzaldehyde (164 $\mathrm{mg}, 1.0 \mathrm{mmol}$ ) and 2-acetylpyridine $(242 \mathrm{mg}, 2.0 \mathrm{mmol})$ in EtOH $(4.1 \mathrm{~mL})$. After $1 \mathrm{~h}$ of the addition of the $\mathrm{NaOH}$ and $\mathrm{NH}_{4} \mathrm{OH}$ mixture, the solution turned red. The solution was then stirred vigorously at room temperature in a flask exposed to air for $17 \mathrm{~h}$, after which a yellow suspension was obtained. Water $(50 \mathrm{~mL})$ was added, and the solution was neutralized with concentrated $\mathrm{HCl}$ to yield a pale yellow precipitate and a red solution. Next, the precipitate was filtered and washed with water. The precipitate was further purified by heating under reflux for $1 \mathrm{~h}$ in $\mathrm{EtOH}(10 \mathrm{~mL})$. The terpyridine-COOH ligand (77.6 mg, 22\% yield) was collected by filtration. ${ }^{1} \mathrm{H}-\mathrm{NMR}$ (DMSO- $\left.d_{6}\right)$ : $\delta 13.2(\mathrm{br} \mathrm{s}, 1 \mathrm{H}), 8.79-8.76(\mathrm{~m}$, $4 \mathrm{H}), 8.69(\mathrm{~d}, \mathrm{~J}=7.9 \mathrm{~Hz}, 2 \mathrm{H}), 8.14(\mathrm{~d}, \mathrm{~J}=8.4 \mathrm{~Hz}, 2 \mathrm{H})$, $8.05(\mathrm{td}, \mathrm{J}=7.6,1.8 \mathrm{~Hz}, 4 \mathrm{H}), 7.56-7.53(\mathrm{~m}, 2 \mathrm{H})$; ${ }^{13} \mathrm{C}$-NMR (DMSO- $d_{6}$ ): $\delta 166.6,155.8(2 \mathrm{C}), 154.9(2 \mathrm{C})$, 149.0 (2C), 148.4, 141.0, 136.9 (2C), 132.4, 129.8 (2C), 126.6 (2C), 124.0 (2C), 120.7 (2C), 117.9 (2C); IR (ATR) $\left(\mathrm{cm}^{-1}\right): \quad v \quad 3414$ (br), 3122, 1684, 1565; HR-ESI-MS: calculated for $\mathrm{C}_{22} \mathrm{H}_{15} \mathrm{~N}_{3} \mathrm{O}_{2} \mathrm{Na}(\mathrm{M}+\mathrm{Na})$ 376.1062, found 376.1061. CAS registry number: 158014-74-5.

2.4 Preparation of PS-PEG resin-supported terpyridine-palladium complex $\mathbf{1}$

A Merrifield vessel was charged with PS-PEG- $\mathrm{NH}_{2}$ $(0.77 \mathrm{~g}, 0.24 \mathrm{mmol})$, terpyridine-COOH ligand $(127 \mathrm{mg}$, $0.36 \mathrm{mmol}), \quad$ 1-ethyl-3-(3-dimethylaminopropyl) carbodiimide (138 mg, $0.72 \mathrm{mmol})$,

1-hydroxybenzotriazole (146 mg, $0.96 \mathrm{mmol}$ ), and DMSO $(10 \mathrm{~mL})$. The reaction mixture was shaken at $25^{\circ} \mathrm{C}$ for $16 \mathrm{~h}$. The consumption of the primary amino residue of the resin was monitored by the Kaiser negative test. The reaction mixture was filtered, and the resin was washed with DMSO and $\mathrm{CH}_{2} \mathrm{Cl}_{2}$. The resin was dried under reduced pressure to provide the polymer-supported terpyridine (loading value of terpyridine: $0.27 \mathrm{mmol} / \mathrm{g}$, as determined by elemental analysis).

Another Merrifield vessel was charged with resin-supported terpyridine ligand (444 $\mathrm{mg}, 0.12 \mathrm{mmol}$ ) and toluene $(10 \mathrm{~mL})$. To this suspension, $\left(\mathrm{C}_{6} \mathrm{H}_{5} \mathrm{CN}\right)_{2} \mathrm{PdCl}_{2}(72.7 \mathrm{mg}, 0.19 \mathrm{mmol})$ was added, and the mixture was shaken (CM-1000) at $25{ }^{\circ} \mathrm{C}$ for $2 \mathrm{~h}$. The mixture was filtered, and the resin was washed with toluene and $\mathrm{CH}_{2} \mathrm{Cl}_{2}$. The resulting resin was dried under reduced pressure to provide the polymer-supported palladium complex 1 (loading value of Pd: $0.26 \mathrm{mmol} / \mathrm{g}$ ). IR (ATR) $\left(\mathrm{cm}^{-1}\right) ; \mathbf{1} ; \mathrm{v} 2868,1653,1453,1094$.

\subsection{Aminocarbonylation}

The general procedure to obtain aminocarbonylation products $\mathbf{4 a}-\mathbf{k}$ is as described here for $\mathbf{4 a}$. Iodobenzene (2a; $81 \mathrm{mg}, 0.40 \mathrm{mmol}$ ) was added to a mixture of polymeric catalyst $(1 ; 77 \mathrm{mg}, 0.020 \mathrm{mmol})$, base $\mathrm{Et}_{3} \mathrm{~N}$ (121 $\mathrm{mg}, 1.2 \mathrm{mmol}$ ), and methoxyamine hydrochloride (2a; $66 \mathrm{mg}, 0.80 \mathrm{mmol})$ in $\mathrm{H}_{2} \mathrm{O}(3.0 \mathrm{~mL})$. The reaction mixture was stirred at $90{ }^{\circ} \mathrm{C}$ for $8 \mathrm{~h}$ under $\mathrm{CO}$ gas $(5.0$ atm) and then filtered. The recovered resin beads were rinsed with $\mathrm{H}_{2} \mathrm{O}$ and extracted thrice with EtOAc $(6 \mathrm{~mL})$. The EtOAc layer was separated and the aqueous layer was extracted with EtOAc $(3 \mathrm{~mL})$. The combined EtOAc extracts were washed with brine $(2 \mathrm{~mL})$ and dried over $\mathrm{MgSO}_{4}$; then, $n$-dodecane $(20 \mathrm{mg}$ ) was added. The GC sample was transferred to a GC vial from the organic layer. The yield of benzamide (4a) determined by $\mathrm{GC}$ analysis was $41 \%$ with $n$-dodecane as an internal standard.

The compounds and CAS registry numbers are as follows: benzamide (4a), 4-methylbenzamide (4b), 4-methoxybenzamide (4c), 4-trifluoro methylbenzamide (4d), 2-methylbenzamide (4e), 3-methylbenzamide (4f), 1-naphthamide (4g), 2-nitrobenzamide $\quad(\mathbf{4 h})$, 2-methoxybenzamide (4i), 4-chlorobenzamide $(\mathbf{4 j})$, and 4-bromobenzamide (4k) and 55-21-0, 619-55-6, 3424-93-9, 1891-90-3, 527-85-5, 618-47-3, 2243-81-4, $610-15-1, \quad 2439-77-2, \quad 619-56-7$, and 698-67-9, respectively.

\section{RESULTS AND DISCUSSION}

The amphiphilic PS-PEG resin-bound terpyridine-palladium complex $\mathbf{1}$ was readily prepared from p-hydroxybenzaldehyde, propane sultone, 2-acetylpyridine, PS-PEG-NH2 resin, and $\left(\mathrm{C}_{6} \mathrm{H}_{5} \mathrm{CN}\right)_{2} \mathrm{PdCl}_{2}$ in accordance with the reported procedures [8, 10]. Polymeric catalyst 1 exhibited catalytic activity for the aminocarbonylation using methoxyamine in water.

Aminocarbonylation of iodobenzene (2a) was performed in water with methoxyamine (3) and catalyst $1(5 \mathrm{~mol} \% \mathrm{Pd})$ in the presence of three equivalents of the base at $90{ }^{\circ} \mathrm{C}$ for $8 \mathrm{~h}$ under $5 \mathrm{~atm}$ of $\mathrm{CO}$ gas. The reaction mixture was filtered and the recovered resin beads were rinsed with a small portion of water and extracted with EtOAc to afford benzamide (4a).

Initially, we screened various bases using iodobenzene as the model substrate for the purpose of the optimization of the reaction conditions. The scope of suitable bases for the aminocarbonylation in water using 
catalyst 1 was examined (Table I). The reaction efficiency greatly varied according to the base used as reported by B. M. Bhanage [7]. The bases lithium carbonate, sodium carbonate, potassium carbonate, and cesium carbonate afforded $\mathbf{4 a}$ in $0 \%, 1.5 \%, 2.5 \%$, and $1.8 \%$ yields, respectively (runs $1-4$ ). The bases sodium hydroxide, potassium hydroxide, and cesium hydroxide afforded $4 \mathbf{a}$ in $19 \%, 2.8 \%$, and $28 \%$ yields, respectively (runs 5-7). Organic amines were found to promote the aminocarbonylation fairly smoothly in water (runs 8-9). The most effective base proved to be triethylamine $\left(\mathrm{Et}_{3} \mathrm{~N}\right)$, which afforded $\mathbf{4 a}$ at $41 \%$ yield (run 8 ). These results mean that an aqueous solution of a strong organic base (e.g. $\mathrm{Et}_{3} \mathrm{~N}$ in $\mathrm{H}_{2} \mathrm{O}: \mathrm{pK}_{\mathrm{b}} \cong 3.0$ ) should promote the formation of the amide $4 \mathbf{a}$ than an aqueous solution of a weak inorganic base base (e.g. $\mathrm{K}_{2} \mathrm{CO}_{3}$ in $\mathrm{H}_{2} \mathrm{O}: \mathrm{pK} \mathrm{k} \cong 4.0$ ) or neutral conditions. We consider that highly basic conditions promote not only demethoxylation of methoxyamide moiety to release formalehyde as reported by B. M. Bhanage [7] but also coupling reaction of anionic end-on intermediate $\mathbf{A}$ (Scheme 2, path I).

If a weak base is used, formation of the $\pi$-methoxyamine-palladium complex $\mathrm{B}$, which cannot undergo reductive elimination to produce the coupling products. Therefore, we decided to use triethylamine as a base these consequences.

Table I. Effect of Base on the Aminocarbonylation of Iodobenzene with Methoxylamine Hydrochloride Using Polymeric Catalyst 1 in Water ${ }^{a}$

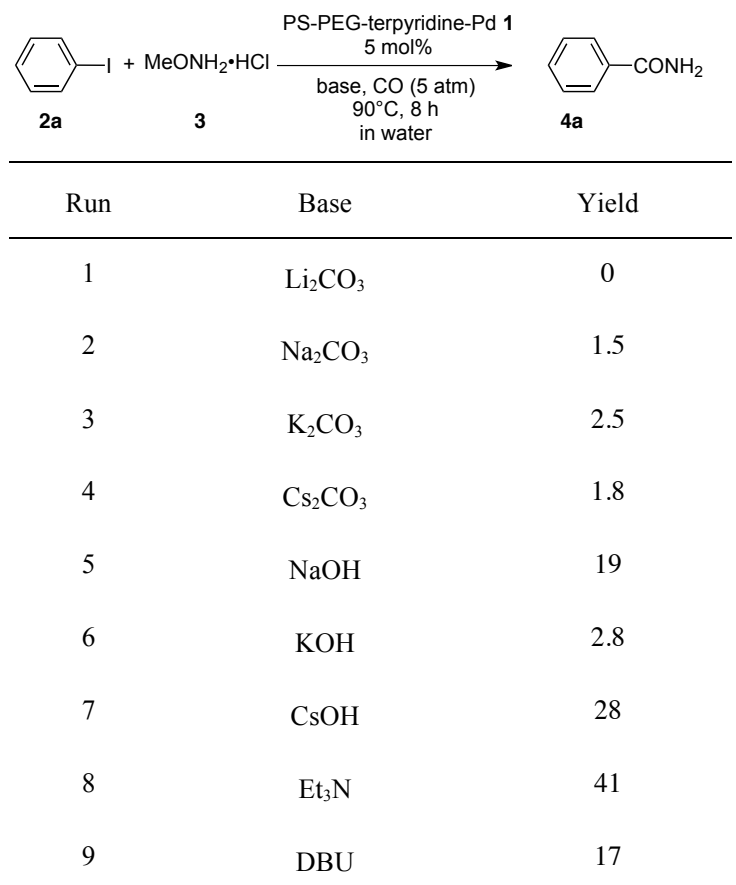

All reactions were performed with iodobenzene (2a; 0.4 $\mathrm{mmol}), \mathrm{MeONH}_{2} \cdot \mathrm{HCl}(\mathbf{3} ; 0.8 \mathrm{mmol})$, and base $(1.2 \mathrm{mmol})$ in the presence of the polymeric catalyst $\mathbf{1}$ in $3.0 \mathrm{~mL}$ of $\mathrm{H}_{2} \mathrm{O}$ at $90^{\circ} \mathrm{C}$ for $8 \mathrm{~h}$ under $\mathrm{CO}$ gas $(5.0 \mathrm{~atm})$.

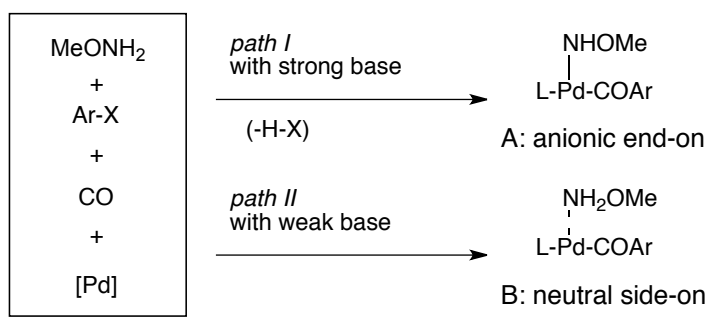

Scheme 2. Weak Base vs. Strong Base in Aminocarbonylation

Table II. Aminocarbonylation of Aryl Iodides with Methoxylamine Hydrochloride Using Polymeric Catalyst 1 in Water ${ }^{a}$

(2)

All reactions were performed with iodobenzene $(2 ; 0.4$ $\mathrm{mmol}), \mathrm{MeONH}_{2} \cdot \mathrm{HCl}(\mathbf{3} ; 0.8 \mathrm{mmol})$, and base $(1.2 \mathrm{mmol})$ in the presence of the polymeric catalyst $\mathbf{1}$ in $3.0 \mathrm{~mL}$ of $\mathrm{H}_{2} \mathrm{O}$ at $90^{\circ} \mathrm{C}$ for $8 \mathrm{~h}$ under $\mathrm{CO}$ gas (atm). 
The scope of suitable aryl iodides for the aminocarbonylation in water using catalyst $\mathbf{1}$ was also examined (Table II). The general process involved conducting the reaction of the aryl iodides with methoxyamine ( 2 equiv.) and $\mathrm{Et}_{3} \mathrm{~N}$ (3 equiv.) in the presence of catalyst 1 ( $5 \mathrm{~mol} \% \mathrm{Pd})$ under $5 \mathrm{~atm}$ of $\mathrm{CO}$ gas in water to afford the corresponding products. The results for various aryl iodides are as follows.

The iodobenzene derivatives $\mathbf{2 b}-\mathbf{d}$ bearing electron-donating (EDG) and -withdrawing (EWG) substituents at their para-positions afforded 4-methylbenzamide (4b), 4-methoxybenzamide (4c), and 4-trifluoromethylbenzamide (4d) in 33\%, 31\%, and $34 \%$ yields, respectively (runs 2-4); meta- and

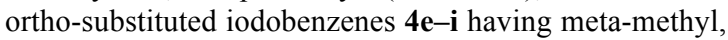
ortho-methyl, meta-nitro (EWG), and meta-methoxy (EDG) groups afforded 2-methylbenzamide (4e), 3-methylbenzamide (4f), 1-naphthamide (4g), 2-nitrobenzamide (4h), and 2-methoxybenzamide (4i) in $31 \%, 33 \%, 34 \%, 33 \%$, and $26 \%$ yields, respectively (runs 5-9). The para-chloro- and

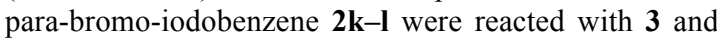
$\mathrm{CO}$ to afford the benzamide derivatives bearing chloroand bromo-substituents $\mathbf{4 j - k}$ in $22 \%$ and $13 \%$ yields, respectively (runs 10-11). The described aminocarbonylation showed a similar reactivity with all substrates, regardless of the substituent effect in the benzene ring of the substrates.

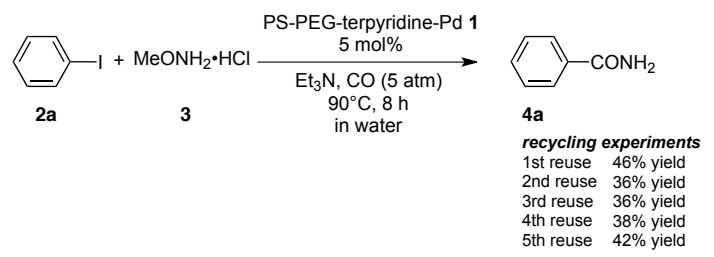

Scheme 3. Catalyst Recycling Experiments

The recyclability of catalyst $\mathbf{1}$ was examined for the aminocarbonylation of iodobenzene 2a with methoxyamine 3 (Scheme 3). After the first reaction, which afforded benzamide (4a) in $41 \%$ yield, the catalyst was recovered by simple filtration, washed with $\mathrm{H}_{2} \mathrm{O}$, dried under a vacuum, and reused twice under similar reaction conditions to afford $4 \mathrm{a}$ in $46 \%, 36 \%$, $36 \%, 38 \%$, and $42 \%$ yields. After recycling experiments, ICP-AES analysis showed that leaching of Pd to the aqueous solution occurred at $<4 \mathrm{ppm}$.

Importantly, ICP-AES analysis of the aqueous phase revealed very low levels of palladium residue.

\section{SUMMARY}

We developed a novel polymer-supported terpyridine-palladium complex that efficiently catalyzes the aminocarbonylation of aryl halides with methoxylamine hydrochloride in water under phosphine-free conditions to afford the corresponding primary amides in good yield.

The catalyst can be recovered and reused several times without any loss of catalytic activity. We are still investigating the scope of the aminocarbonylation with the other nucleophiles and possible applications of the catalyst to other organic transformations.

\section{ACKNOWLEDGEMENTS}

We are grateful for the financial support from the Young Scientists Program of University of the Ryukyus. We also thank the Cooperative Research Center for financial support. Finally, we thank Shohei Maehara and Akitada Sunagawa, undergraduate students, for assistance with some of the analytical experiments.

\section{REFERENCES}

[1] S. Roy, S. S. Roy, and G. W. Gribble, Tetrahedron, 68, 9867-9923 (2012).

[2] (a) K. Soai, A. Ookawa, and H. Hayashi, J. Chem. Soc. Chem. Commun., 12, 668-669 (1983) (b) A. Prasad, J. Kanth, and M. Periasamy, Tetrahedron, 48, 4623-4628 (1992).

[3] (a) D. Bose and B. Jayalakshmi, J. Org. Chem., 64, 1713-1714 (1999). (b) K. Chaudhari, U. Maharajan, D. Bhalerao, and K. Akamanchi, Synlett, 2815-2818 (2007).

[4] B. F. Plummer, M. Menendez, and M. Songster, $J$. Org. Chem., 54, 718-719 (1989).

[5] (a) A. Schoenberg, I. Bartoletti, and R. F. Heck, $J$. Org. Chem., 39, 3318-3326 (1974). (b) A. Schoenberg and R. F. Heck, J. Org. Chem., 39, 3327-3331 (1974). (c) A. Schoenberg and R. F. Heck, J. Am. Chem. Soc., 96, 7761-7764 (1974).

[6] (a) X.-F. Wu, H. Neumann, and M. Beller, Chem. Soc. Rev., 40, 4986-5009 (2011). (b) A. Brennfuhrer, H. Neumann, and M. Beller, Angew. Chem. Int. Ed., 48, 4114-4133 (2009). (c) T. Shibata, Adv. Synth. Catal., 348, 2328-2336 (2006). (d) D. Strubing and M. Beller, Top. Organomet. Chem., 18, 165-178 (2006). (e) A. M. Trzeciak and J. J. Ziolkowski, Coord. Chem. Rev., 249, 2308-2322 (2005).

[7] S. T. Gadge and B. M. Bhanage, Synlett, 25, 85-88 (2014).

[8] (a) T. Suzuka, M. Adachi, Y. Nakamoto, and K. Ogihara, Trans. Mater. Res. Soc. Jpn., 40, 77-80 (2015). (b) T. Suzuka, M. Adachi, and K. Ogihara, Trans. Mater. Res. Soc. Jpn., 40, 103-106 (2015). (c) T. Suzuka, H. Sueyoshi, S. Maehara, and H. Ogasawara, Molecules, 20, 9906-9914 (2015). (d) T. Suzuka, M. Adachi, Z.-S. Yang, K. Ogihara, and M. Higa, Trans. Mater. Res. Soc. Jpn., 38, 119-122 (2013).

[9] Polymer-supported phosphine-Pd complex for carbonylation: (a) Y. Uozumi and T. Watanabe, J. Org. Chem., 64, 6921-6923 (1999). (b) H. Gao, Y. Xu, S. Liao, and D. Yu, React. Polym., 23, 113-118 (1994).

[10] (a) For a review of terpyridine-metal complexes, see I. Eryazici, N. Moorefield, and R. Newkome, Chem. Rev., 108, 1834-1895 (2010) and references therein.

(Received January 12, 2016; Accepted March 10, 2016; Published Online September 1, 2016) 